\title{
A ELABORAÇÃO DO LUTO E AS DIFICULDADES DE DESLIGAMENTO NO PÓS-TÉRMINO DE ANÁLISE
}

\section{Yeda Alcide Saigh}

Resumo: A autora discute as dificuldades do término das análises como equivalente a um estado de luto que tem características específicas, considerando, dentre outros conteúdos teóricos, o que diz Melanie Klein (1991):"o término de uma análise reativa no paciente situações mais arcaicas de separação e tem a natureza de uma experiência de desmame" (p. 65). Além disso, estuda também o luto pelo término no mundo dos analistas, considerando as análises didáticas e a especificidade dessa relação: os candidatos podem esperar manter relacionamento de colegas com seus analistas depois do término; mas os "pacientes comuns" típicos não podem contar com qualquer tipo de contato e, assim, é provável que sofram uma reação de luto muito mais intensa que os candidatos. Todas essas considerações contribuem para demonstrar que o luto é tema relevante, a ser considerado nos estudos psicanalíticos sobre o término e o pós-término das análises.

Palavras-chave: Psicanálise. Luto. Término da análise.

\section{Elaboração do Luto}

Procurarei analisar aqui, para conhecê-los melhor, o pensamento e as ideias de diversos autores que escreveram sobre a elaboração do luto no pós-término das análises. 
O tema do luto é um tema recorrente na literatura sobre o pós-término. Vários autores consideram que o luto pela perda do analista só se completa muito tempo depois de cessados os encontros entre analista e analisando.

É muito difícil, quase impossível, estabelecer regras gerais para qualificar o processo de término da relação analítica. A maioria dos autores que escreveram sobre esse tema dão exemplos de casos clínicos, considerados seus diferentes postulados teóricos ou ideias a respeito. Quase todos discutem um ponto quase autoevidente e que se refere ao processo de luto que se instala no período aqui definido como "pós-término", diante da perda da relação analítica. Nenhuma das contribuições oferece uma pauta geral que se possa aplicar ao término de análise; pode-se concluir que existem tantas modalidades de término de análise quanto análises existem.

Da mesma forma, pode-se afirmar que a elaboração do luto acaba de se realizar no período de pós-término, independentemente de que modalidade de pós-término se considere, em cada caso. Essa ideia de um sofrimento muito grande pela separação do analista — um luto — é partilhada por muitos outros autores da comunidade psicanalítica.

A vivência de um luto desencadeia-se a partir do momento em que analista e analisando chegam a um consenso a respeito de uma data prevista para o término, ou a partir do momento em que um dos dois anuncia a intenção de pôr um fim aos encontros analíticos.

Em “Análise Terminável e Interminável",Freud (1937/1975) já escrevia:

a informação que o paciente recebe do analista de que seu tempo concreto ali com ele está prestes a se esgotar, seja ele um ano ou seis meses ou qualquer outra duração, ocasiona-lhe um alto grau de turbulência em seu mundo mental e funciona como pressão sobre conteúdos reprimidos ${ }^{1}$, podendo também desencadear fantasias de rejeição e abandono, antes não trabalhadas. (p. 250)

Freud nos alerta que "pode levar ao sepultamento de material psíquico comprometendo sua elaboração" (p. 252).

Em minha dissertação de Mestrado escrevi:

Assim como revelou Freud, o luto é uma reação à perda de um ser muito querido, que mobiliza um estado muito penoso para o indivíduo, o qual desinveste sua libido dos acontecimentos exteriores e se volta para si mesmo. $O$ teste de realidade provou-lhe que o objeto amado já não existe, mas o indivíduo enlutado deixa de se interessar por tudo que não se relacione a essa pessoa.Pouco a pouco

1 Em alemão, Verdrängung; em francês, quase sempre refoulement. Mantemos aqui a tradução que se encontra na edição citada, embora haja discussão importante sobre o conceito de 'repressão' para traduzir o termo alemão. Autores importantes nem sempre correm o risco de traduzir este termo complexíssimo, Lacan, por exemplo."La Verdrängung est inhérente au désir" (Lacan, 1966, p. 694); em outros momentos, a tradução está feita ("C'est la loi propre de la chaîne signifiante qui régit la forclusion (Verwerfung), la dénégation (Verneinung), le refoulement (Verdrängung)" (p. 11). 
o trabalho de luto vai possibilitando uma retirada da libido investida naquele ser amado e criando condições para que o ego volte a ficar "livre e desinibido" (Freud, 1917). A libido se torna novamente disponível para que o ego faça novos investimentos libidinais. (Saigh, 2002 p. 26)

Embora a elaboração do luto pela perda dos encontros com o analista seja um processo doloroso que se inicia ainda na vigência da análise e se prolonga pela vivência do pós-término, acredito que ela possa ser facilitada pelos ganhos que o analisando se dá conta de que teve com a análise. De que ganhos estou falando? Desde ganhos de ordem prática (por exemplo, mais tempo e dinheiro disponíveis para investir em outras atividades), até ganhos de ordem psíquica, tais como a internalização por parte do paciente da função antes exercida pelo analista, o desenvolvimento de confiança em sua autonomia, em outras palavras, em sua capacidade de caminhar com as próprias pernas. Ainda que isso signifique um certo desamparo, a sensação de liberdade parece compensar. Como ouvi uma vez do analista já falecido, Dr. José Longman, "There is a point of no return" (Existe um ponto do qual não há retorno). É o momento em que o analisando sente e o analista capta que está na hora de se despedirem.

Ainda com relação a ganhos obtidos através do processo de análise e que podem constituir fatores decisivos para favorecer uma satisfatória elaboração de luto, estudos mencionados por Craige (2002) indicam que depois de uma análise bem-sucedida o analista razoavelmente bom tornase traço permanente na mente do analisando, oferecendo um útil novo objeto interno de apoio. Desse modo, depois de o analisando ter feito o luto pela perda do relacionamento quase diário com o analista, o analisando pode vir a sentir-se enriquecido, em vez de empobrecido, pela perda.

Melanie Klein, em seu artigo de 1950, nos diz que a elaboração do luto é favorecida pela possibilidade de o indivíduo integrar diferentes aspectos do objeto perdido e não se deixar levar por fantasias inconscientes de, junto com ele, ter perdido também seus objetos internos bons. A separação do objeto, dependendo de como ocorra, pode despertar uma ansiedade paranoide (caso em que a pessoa se sente abandonada ou atacada pelo objeto), ou uma ansiedade depressiva (caso em que a pessoa teme perder a segurança que lhe era oferecida pelo objeto). A qualidade da experiência vivida com o analista enquanto objeto real, externo, vai afetar a possibilidade de que o luto pelo término da análise seja elaborado satisfatoriamente. Para que o luto pelo término seja satisfatoriamente elaborado, é necessário que ele tenha sido internalizado de forma estável, como um objeto bom e confiável.

Para Klein (1950/1991), o término de uma análise equivale a um estado de luto. Observa-se frequentemente que "o término de uma análise reativa no paciente situações mais arcaicas de separação e tem a natureza de uma experiência de desmame" (p.65). 
Seu critério para a terminação é o seguinte:

Minha abordagem ao problema do término de análises, tanto de criança quanto de adulto, pode ser definida da seguinte forma: a ansiedade persecutória e a depressiva deveriam estar suficientemente reduzidas e isso - em minha concepção - pressupõe a análise das primeiras experiências de luto. (p.67)

No mesmo trabalho de 1950, Melanie Klein escreve que, mesmo quando resultados satisfatórios são alcançados, o término de uma análise fatalmente desperta sentimentos dolorosos e revive ansiedades arcaicas. Quando a perda representada pelo final da análise ocorre, o paciente ainda tem que se encarregar por si mesmo de parte do trabalho de luto.

A perda e o luto do final da análise têm uma qualidade especial que os diferencia da perda por morte: são componentes fundamentais do vínculo transferencial e contratransferencial. A renúncia à fusão com o objeto é a base do trabalho do luto. $O$ trabalho do luto imposto pelo teste da realidade faz com que o indivíduo renove os seus elos com o mundo exterior e reconstrua dolorosamente o mundo interior. No término da análise existe um reviver desses lutos primordiais, que vão ser retomados com o analista na transferência.

Num simpósio organizado pela Sociedade Britânica em março de $1950^{2}$, sobre o tema Término de Análise, Balint apresentou um trabalho em que dizia:

É uma experiência profundamente mobilizadora; a atmosfera geral é a de despedir-se para sempre de alguém muito querido, muito precioso - com os correspondentes sentimentos de desolação e luto - mas este pesar sincero e profundamente sentido é mitigado pelo sentimento de segurança que se origina das recém-conquistadas possibilidades para uma felicidade real. Habitualmente o paciente na última sessão parte contente mas com lágrimas nos olhos - e penso poder admiti-lo -, o analista vivencia algo muito semelhante. (p. 197)

Segundo Rickman (1950), a capacidade de elaborar o luto constitui um dos principais critérios que o analista deve levar em conta para pôr término a uma análise.

Para Annie Reich (1950), é inevitável que se sinta o término de uma análise como uma perda, especialmente para aquelas pessoas que não são felizes com a sua vida real e para as quais uma mudança objetal é muito difícil. Depois de um certo tempo e de uma análise completa, sem dúvida essa mudança pode ocorrer e o desejo de manter uma relação infantil com o analista pode ser abandonado.

A autora pensa que não devemos nos preocupar com os resultados negativos dos resíduos transferenciais, porque, assim como se observa no

Todos os trabalhos apresentados nesse Simpósio se encontram publicados no volume 31 do International Journal of Psychoanalysis. 
luto, também aí surge uma recuperação espontânea; bem se pode dizer que é um recuperar-se da situação "anormal da análise".

Outros autores continuaram a ocupar-se da questão da necessidade de elaborar o luto como questão associada ao término de análise. Alguns distinguem o luto pelo término da análise do luto pela separação do analista - como pessoa real e como objeto transferencialmente investido.

Hanna Segal (1997/1998) salienta que a proximidade do fim da análise é responsável pela emergência de antigas angústias e defesas; acredita, entretanto, que a mobilidade psíquica conquistada pelo paciente através do processo analítico o instrumenta a simbolizar, através dos sonhos, fantasias e material associativo, os conteúdos ligados à situação de perda que está sendo experimentada. Isso preparará o paciente para lidar com a perda e introjetar o objeto que desenvolverá a função analítica.

Ticho, em artigo publicado em 1972, não considera o luto como um dos principais fatores para o término, mas diz: “Embora a terminação da análise também implique luto e desapontamento, o paciente, quase sempre, experiencia essa fase como um novo começo" (p. 325).

Segundo Goldberg e Marcus (1985):

Uma data tem o efeito de ativar uma reação de luto e a repetição regressiva de velhas defesas observadas durante este período tem um tom de renúncia. Pode-se pensar no último passo do processo de término como um luto por todas as perdas de objeto passadas e como uma antecipação do luto por outra perda - a do analista. Elaborar este tipo de "trabalho de término" oferece uma oportunidade que não se tem de nenhum outro modo. (p. 55)

Com a perda real do analista, como já mencionado, o paciente tem de lidar com um processo de luto, seguido pela consolidação do objeto no ego. Chamamos este objeto de objeto analítico.

Em 1938, Schmideberg, em "After the Analysis", faz o seguinte comentário:

O paciente às vezes desloca a valorização narcísica de si mesmo para a análise; insistirá que a análise é muito superior a qualquer outro método de tratamento, e não admitirá que exista qualquer coisa fora dela, assim como no passado sentiu-se superior a todas as crianças e desejou que seus irmãos e irmãs não existissem. (p. 125)

O narcisismo, assim deslocado do eu infantil para o processo de análise, pode ser um fator que dificulte que o paciente aceite interromper a análise e elabore o luto pela perda dos encontros analíticos.

Craige (2002), em seu artigo "Mourning Analysis: The Post-termination Phase", estuda as diferenças que há, na elaboração do luto do analista, entre o que chama de "pacientes comuns" e os terapeutas que fazem suas análises didáticas, designados aqui como "candidatos".Para ela: 
Enquanto os candidatos podem esperar manter relacionamento de colegas com seus analistas, depois do término, os "pacientes comuns" típicos não podem contar com qualquer tipo de contato e, assim, é provável que sofram uma reação de luto muito mais intensa que os candidatos. (p.537)

Além disso, os candidatos, por já terem passado, em sua maioria, antes de se submeterem a análise didática, por outros processos psicanalíticos, já desenvolveram recursos que os preparam melhor para o exercício da autoanálise, o que favorece a elaboração do luto pela separação; pelo mesmo motivo, supõe-se que estejam mais preparados que os pacientes leigos para se libertarem dos resíduos da transferência, após o término.

Nessa comparação, é importante não esquecer que os "pacientes comuns" não têm qualquer tipo de conhecimento ou de treinamento que os preparem para a exposição diária "ao perturbador material emocional" que sempre está "em pauta", sempre "ao vivo", para os profissionais da saúde mental. Nem são "obrigados" a manter relações sociais com seus analistas, ou a enfrentar a política organizacional dos psicanalistas, o que, para os candidatos, pode provocar dolorosos estados de desidealização.

Craige (2002) cita Orgel (2000), que diz: "nenhum processo interno substitui inteiramente a relação analítica". $E$, "nenhum relacionamento jamais preenche o desejo infantil básico da completude narcísica"; por isso [também],"o luto das esperanças não realizadas pela análise pode nunca ser completo" (p.538).

Bergmann (1988), em seu artigo"On Fate of the Intrapsychic Image of the Psychoanalyst After Termination of the Analysis" concorda com vários autores quando diz que não importa o quanto se estenda a fase do término, num certo momento ela sempre será interrompida abruptamente.

Um relacionamento que foi rico em transações interpessoais tem de transformarse em relacionamento intrapsíquico. Não há nada, na vida real, que se compare à experiência do término. Não surpreende que tão freqüentemente os analisandos associem o término à morte. (p. 137)

Ao referir-se a relacionamento intrapsíquico, penso que Bergmann está tratando do que tenho chamado de "função analítica".

Pellanda (1991), em seu artigo"A Fase Pós-análise:Vicissitudes de um Luto", diferencia pacientes que após a análise são capazes de enfrentar sozinhos a vida do pós-término de outros que, por não conseguirem introjetar um objeto analítico, necessitam de um acompanhamento ad eternum de um analista: seria o que chamei de "análise interminável (Modelo D)",na minha dissertação de Mestrado (Saigh, 2002). Para Pellanda (1991), essa seria uma das vicissitudes para a elaboração do luto.

Baulkoura (1974), em seu artigo "The fate of the tranference neurosis after analysis scientific proceedings: worshop report", sugere que a realiza- 
ção de estudos de acompanhamento possa retardar ou obstruir o processo de elaboração natural do luto durante a fase do pós-término.

Estamos aqui às voltas com uma questão espinhosa. Embora eu considere de relevante interesse científico o estudo do pós-término - e daí meu interesse no tema -, é preciso considerar também que a metodologia utilizada deve levar em conta esse dado efeito dos procedimentos de pesquisa sobre os pacientes. Os sujeitos da pesquisa podem ser prejudicados em sua elaboração do luto característico da fase em apreço.

Craige (2002), tendo procedido a uma extensa revisão bibliográfica a respeito do pós-término, com ênfase na questão do luto, escreve que o luto ecoa através da literatura analítica sobre o término. Muitos analistas que escrevem sobre o término observam que o luto pela perda do analista nunca chega a se completar até bem depois de paciente e analista terem deixado de encontrar-se. Cita Buxbaum (1950), Weigert (1955), Reich (1950), Deutsch (1959), Ticho (1972), Loewald (1962), Blum (1988), Berenstein e Fondevila (1989), Rucker (1993), Orgel (2000) (p. 509).

Todos esses trabalhos baseiam-se na compreensão psicanalítica do luto como uma resposta normal a qualquer perda significativa, inclusive à perda do analista, no término, que se resolve pela internalização do objeto amado perdido. Moore e Fine (1990), citados no trabalho de Craige (2002), definem o luto como o processo mental pelo qual o equilíbrio mental de alguém é restaurado, depois da perda de um objeto amado significativo. Refere que para Loewald (1960) o modo como o analisando faz o luto e internaliza o analista indica se a separação do analista será experienciada como privação e perda ou como desenvolvimento. Embora muitos escritores no campo analítico considerem esperado e previsto o período de luto depois do término, Sheppard (1998) cita em seu artigo um estudo de Lord, Ritvo e Solnit (1978), que concentra-se nos casos raros de analisandos cujos analistas morrem durante o tratamento, visto como um específico processo de luto.

Segundo Craige (2002), uma história pessoal de perda e privação precoces parece ser o fator mais importante associado ao luto patológico depois de análise terminada ou interrompida. Alguns autores discutem se o luto pelo analista no término é feito primordialmente por um objeto de transferência ou por um objeto real. Para Novick (1976), o analisando faz o luto pelo analista como objeto de transferência.

Conway (1999), em seu artigo "When all is Said... A Phenomenological Enquiry into Post Termination Experience", salienta que, em determinados casos, na fase do pós-término, o luto possa ser vivido como um sentimento de perda não só do analista real mas também como uma perda temporária dos ganhos obtidos no trabalho de análise; pode acontecer, escreve a autora, de os sintomas voltarem por algum tempo e as palavras do analista parecerem ter sido esquecidas. 
Guignard (1997) em seu artigo "Après L'analyse", publicado na Rêvue Française de Psycanalyse, chama a atenção para o fato de que:

o trabalho de luto do analisando tem seu duplo especular no analista: é o trabalho de fazer-se morrer ele mesmo. Esse é o limite extremo da abstinência analítica: mais do que se pôr à vista do analisando, num espírito messiânico, o analista deve aceitar "que ele cresça e que eu diminua".(p. 1222)

\section{Dificuldades de desligamento}

Antes de comentar os problemas do desligamento que se evidenciam no pós-término, gostaria de fazer algumas considerações sobre as dificuldades relativas à separação que ocorrem ainda durante a fase do término.

$\mathrm{O}$ analista precisa estar instrumentado para lidar com os mais diferentes tipos de resposta emocional do analisando que está terminando a análise. Precisará, para tal, confrontar-se com seus próprios lutos. $O$ analista também requer cuidados especiais com ele próprio na fase do "desmame analítico" e seus sentimentos necessitam ser incluídos e examinados por ele próprio, favorecendo o trabalho do término.

Para o paciente, continuar sozinho não é tarefa fácil; a perda do colo, do envelope protetor, todas essas sensações quase físicas são mobilizadas na fase do término e necessitam muita interpretação do analista a fim de serem suficientemente elaboradas, para que o paciente "ganhe asas".

A perspectiva de não mais voltar a encontrar seu analista provoca no analisando um sentimento de pesar,é vivida por este como uma perda que faz aflorarem outras perdas sofridas anteriormente. As reações depressivas podem ser de tal modo intensas que tornam necessário um adiamento do término, até que o analista julgue que o analisando está pronto para lidar com seu sentimento de solidão.

Quando o desligamento foi bem elaborado, a ausência ou a presença do analista deixam de desencadear angústias de separação e de desmoronamento, pois o analisando entra num estado de sustentação mais eficiente, torna-se autônomo, pode ficar só, sentindo-se acompanhado. Entretanto, certos analisandos experimentam uma enorme dificuldade de separar-se do analista.

Segundo Rosenfeld (1987/1988), analisandos com graves distúrbios narcísicos de personalidade podem apresentar significativas dificuldades de desligamento do analista. Como não reconhecem o objeto como existindo separado do self, alimentam a fantasia de a eles se manterem fundidos, o que se torna um empecilho ao término da análise. 
Bick (1968/1991), ao observar bebês, se deu conta de que o bebê passa por um estado de não-integração, bastante primitivo, em que precisa de um objeto continente. Tal objeto lhe proporcionará a sensação de estar integrado, ainda que por poucos momentos; pode ser representado pelo mamilo da mãe, pelo seu cheiro, seu calor, sua voz, fazendo as vezes de uma "segunda pele". A autora descreveu um tipo de "identificação adesiva" que poderia explicar algumas dificuldades experimentadas pelo analisando em relação ao analista; nessas situações, o analisando teria delegado ao analista a função de pele continente, mas essa profunda dependência estaria mascarada por uma pseudoindependência.

Tanto na primeira categoria de pacientes - aqueles que sofrem de profundos distúrbios narcísicos de personalidade — como na segunda aqueles que fazem uma identificação "adesiva" com o analista —, surgirão também dificuldades na fase do pós-término. Esses pacientes dificilmente internalizam o objeto analítico e mesmo após encerrada a análise voltam a procurar o analista tão logo se deparem com alguma situação nova que represente conflito e mobilize angústia. Quanto aos pacientes narcísicos mencionados por Rosenfeld, tenho verificado em minha prática que eles dificilmente conseguem sobreviver sem um acompanhamento analítico. Isso está ilustrado em minha dissertação de mestrado no "Caso D, Análise Interminável"(Saigh, 2002).

Em 1938, Schmideberg, em "After the Analysis", observou que, para alguns pacientes, a análise é uma fuga da vida, uma volta à infância. Esse tipo de paciente vive literalmente pela análise e para a análise. Ele se sentirá culpado se tiver de lidar com uma dificuldade ou se superar uma crise emocional, se ambas não tiverem sido analisadas antes; em resumo, acha que nada consegue resolver sem a análise. Quer que a análise o proteja da realidade, como seus pais o protegeram da vida; quer continuar a ser um bebê e adia qualquer esforço ou decisão desagradável para quando a situação estiver "completamente analisada", com a expectativa de que a vida, depois do trabalho analítico, seja mais fácil, sem ter de fazer qualquer esforço. Não será necessário renunciar a nada e qualquer decisão que tome jamais custará qualquer dor.

No mesmo texto, a autora chama a atenção para "o momento certo de parar."Concordo com ela quando diz que se devem pesar as vantagens de continuar o tratamento em relação às desvantagens, e também levar em consideração os efeitos psicológicos de grandes sacrifícios impróprios e outras inconveniências. Se o analisando sente, talvez com alguma justificativa, que o analista espera que ele considere a análise como a coisa mais importante que faz em sua vida, e pela qual o analisando deveria trocar a grande maioria de seus prazeres - comprar roupas, jantar em restaurantes, viajar - em função do custo da análise, nesses casos será difícil analisar a inibição do prazer no analisando. 
Tenho observado, conversando com colegas e na minha própria prática profissional, que há situações em que o analisando delega as soluções de todos os problemas de sua vida ao analista e à análise, quase escravizando-se, e negligencia outros investimentos que seriam prioritários naquele momento de sua vida. Lembro-me de uma analisanda que, às voltas com grandes dificuldades financeiras, postergava um tratamento dentário imprescindível. Penso que, no caso das instituições psicanalíticas, às vezes ocorre uma deformação do sentido da análise. Por exemplo, durante o período de formação na SBPSP, alguns candidatos a analistas que moram no interior de São Paulo, ou em outro estado, fazem enormes sacrifícios em termos financeiros e também do tempo que poderiam dedicar a sua atividade pessoal e profissional. Como os cursos e análises condensadas ocorrem no começo da semana, tais profissionais são obrigados a se deslocarem de suas cidades de origem todas as semanas, a trabalharem parte do fim de semana para compensar o tempo passado em São Paulo, comprometendo muito sua qualidade de vida durante o tempo da formação. No caso de analisandos leigos, seu investimento em análise chega a se tornar insensato, e às vezes o analista perpetua essa situação ao endeusar a análise e o analista, o que seria um desserviço ao analisando que, às vezes, não se encontra em situação de avaliar realisticamente as suas condições de vida e muito menos de se encorajar sozinho a tomar a decisão de terminar a análise, ainda que temporariamente. Creio que nessa questão o bom-senso é soberano.

Sinto-me respaldada, nesta minha maneira de pensar, pela opinião emitida por Green (2000) em seu livro Le Temps Eclaté:

uma longa análise em diferentes períodos parece ter melhores chances de obter modificações estruturais que uma única análise realizada num ritmo intenso five times a week (cinco vezes por semana, somente com a finalidade de respeitar o sacrossanto fim de semana), segundo as exigências formais de nossos colegas anglo-saxões. (p. 62)

Muitas análises de formação ou didáticas se ressentem dessas formalidades, a ponto de observarmos colegas que fazem uma verdadeira contagem regressiva e, mal completam os cinco anos exigidos pelos Estatutos da Instituição, interrompem o processo, se "dando alta".

Os intervalos, segundo Green, irão minimizar eventuais dificuldades de desligamento na medida em que exigirão do analisando, a cada interrupção, uma elaboração do luto. Na esteira dessa mesma idéia, acredito que o analisando, ao interromper a análise, mesmo que temporariamente, com a anuência de seu analista, desenvolve a confiança de poder caminhar com as próprias pernas e contar com seus próprios recursos, ainda que enfrente dificuldades. Nessa mesma obra, Green chama a atenção para o fato de que às vezes uma decisão do analisando, de interromper a análise, pode 
ser considerada pelo analista como um sintoma, devendo ser tratada com tato e habilidade. Diz ele:

Sem dúvida é mais sensato liberar o analisando e suspender o processo analítico na expectativa de que as circunstâncias venham a reatualizar a necessidade de prossegui-lo, permitindo a 'reabertura' da brecha pela qual o inconsciente se infiltrou, às vezes excessivamente. (p.62)

Do ponto de vista do analista, algum risco também se coloca. Como as análises atualmente duram mais tempo (oito, dez, doze e ate mais anos), o analista fica restrito a um pequeno número de pacientes que permanecem, e sua clínica resulta pouco diversificada.

Schmideberg, em 1938, havia alertado para outro risco envolvido na maior duração das análises:

O perigo de nossa atitude recente, de tentar manter o paciente pelo tempo mais longo possível, é que nos comportamos de modo muito semelhante aos pais possessivos, que fazem com que os filhos passem a ter medo da vida, porque não querem que os filhos cresçam e se separem deles. (pp. 134-135)

Dificuldades de desligamento permeiam todo o processo da análise, tornando-se mais evidente nas interrupções de fim de semana, férias e, principalmente, no prenúncio do término da análise. Na fase do pós-término, tais dificuldades podem evidenciar-se de diferentes maneiras: ou através de reações depressivas que sugerem a impossibilidade de elaborarem satisfatoriamente o luto, ou através de atuações que revelam, além de uma grande turbulência interna, uma evidente dificuldade de aceitarem o fim dos encontros analíticos. Para ilustrar, lembrei-me de uma analisanda que telefonava insistentemente e chegou a comparecer a uma sessão em seu antigo horário. Somente ao encontrar o paciente que agora ocupava tal horário ela se deu conta da realidade dos fatos.

Talvez a maior dificuldade de desligamento resida na ansiedade de separação que é revivida quando se aproxima o final da análise.

Vários autores concordam quanto à importância de se trabalhar a ansiedade de separação que emerge quando a análise se encaminha para sua etapa final, mas a ansiedade ou angústia de separação não aparece apenas porque uma análise está para acabar: ela permeia a situação da análise e a nossa vida a todo instante. A angústia de separação está, então, onipresente no processo da análise, assim como na vida. Torna-se mais evidente no material associativo do analisando, quando já se fixou uma data para o término.

Em 1924, Otto Rank escrevia que uma das dificuldades que os pacientes têm para deixar a análise é o medo de nunca mais ver o analista, uma das reações que simbolizam nascimento e morte, experiências fundamentais de separação que todo ser humano necessariamente enfrenta. 
Melanie Klein observou que o término de uma análise mobiliza no analisando situações arcaicas de separação; por isso, ela equipara essa fase à experiência de desmame. Balint adota uma perspectiva semelhante ao comparar a separação entre analisando e analista à experiência do nascimento.

Em 1950, Parres comenta que, ao se convencer de que a análise oferece formas ilusórias de satisfação e sentindo-se encorajado a buscar alternativas mais realistas de gratificação, o analisando acaba por separar-se lenta e decididamente da análise, elaborando assim o luto pela separação.

Miller, em 1965, refere que Ticho considera a reação pós-analítica de desapontamento mais comum do que normalmente se admite. Tratando dessa questão, Miller escreve que uma maior consciência da reação de desapontamento levaria a uma cuidadosa análise, na fase de término, do modo como o analisando lidou com seus desapontamentos no passado, e permitiria que o analista conectasse aquelas reações com o processo de luto e ansiedade de separação características da última fase da análise. Isso não eliminaria, nem deveria eliminar, o desenvolvimento da reação de desapontamento; mas daria ao analisando uma maior chance de lidar construtivamente com seus desapontamentos.

Ferraro e Garella, ao fazerem uma revisão, em 1994, sobre formas de término da análise, observam:

Um pré-requisito fundamental deste processo pode ser individualizado nas modificações sofridas pela angústia de separação que, como outros analistas já assinalaram (Bridger, 1950; Rickman, 1950; Liberman, 1967), pode converterse em critério-guia por excelência para a decisão de terminar.... esta é a síntese e o resultado final de complexos processos de integração que criaram um espaço psíquico temporo-espacial de relação, espaço de natureza diferente do que reina na angústia de separação. (p.92)

Em relação à vivência mais significativa do pós-término, Green (2000) refere tratar-se de um desenraizamento de tal modo penoso que a palavra luto não é, em absoluto, de modo algum, excessivamente forte para a ele referir-se. Segundo ele:

cessando a análise um grande vazio se instala. Falta do objeto de transferência? Com certeza, mas não unicamente. Vacância de um tempo que se oferece à exploração de si por si mesmo? Desdobramento em que aquele que busca é o próprio objeto da busca e tem assim necessidade de um outro para ouvi-lo? Sobretudo, sentimento de um veredicto que se anuncia:"é realmente necessário aí permanecer, renunciar a toda esperança de mudança futura?" Interrogações que não trazem sempre respostas mas relançam perpetuamente a questão: "Quem sou eu? Quem fui eu? Que será de mim?" Muito mais do que "Que posso eu esperar?" pois ter esperança não depende de autorização de ninguém. (pp. 61-62) 
Os dois temas que abordei nesse artigo, elaboração do luto e dificuldade de desligamento, são interligados. O desligamento do analisando, quando é bem elaborado, leva ao luto; se não, leva à melancolia. As pessoas melancólicas carregam por muito tempo a pessoa da qual se desligaram, como se ela ainda fizesse parte de suas vidas. A incapacidade para encarar a realidade da perda é tão insuportável que, nesses casos, há quem se apegue até a coisas materiais, roupas, fotos, cartas, para terem a ilusão que não estão separadas, que continuam juntas. Como diz André Green, o vazio que se instala no término de uma análise levanta inúmeros questionamentos, às vezes ainda sem resposta.

\section{The elaboration of mourning and the difficulties of separation in the post-ending period}

Abstract: The author presents and discusses the difficulties of the ending of the psychoanalysis, as equivalent to a state of mourning that has specific characteristics, as established among other authors, Melanie Klein (1991):"the ending reactivates in the patient more archaic situations of separation and has the nature of an experience of weans" (p. 65). The mourning of the ending of psychoanalysis has to be studied, also, in the context of the analysts, considering the didactic analyses and in the specificity of this relation. Candidates can count on the probability that they will have contact with their fellow analysts after the ending; but the typical "common patients" cannot count on any type of contact and, thus, it is probable that they suffer a much more intense mourning effect than in the case of the candidates. All these considerations contribute to demonstrate that mourning is an important subject, to be considered in psychoanalytical studies on the ending and the after-ending of analyses.

Keywords: Psychoanalysis. Grief. End of analysis.

\section{L'Élaboration du deuil et les dificultés de la séparation dans la période d'après-analyse}

Résumé: L'auteur présente et discute les difficultés de la fin des psycho-analyses, comme l'équivalent à un état de deuil qui a des caractéristiques spécifiques comme le disent plusieurs auteurs et aussi Melanie Klein (1991): "la fin réactive dans les analisands des situations plus archaïques de séparation et a la nature d'une expérience de sevre" (p.65). D'une part, le deuil de la fin de la psycho-analyse doit être étudié, aussi, dans le monde des analystes, en considerant les analyses didactiques et l'especificité de cette relation. Les candidats peuvent compter sur la probabilité qu'ils auront des contacts avec leurs analystes, dans la vie sociale, après la fin; mais "les 
patients communs typiques" ne peuvent pas compter sur aucun type de contact et, ainsi, il est probable qu'ils souffrent un effet de deuil beaucoup plus intense que dans le cas des candidats. Tous ces considerations contribuent pour démontrer que le deuil est un sujet important, pour être considéré dans des études de psycho-analyse sur la fin et l'après-fin des analyses.

Mots clés: Psycho-analyse. Deuil. Fin de l'analyse.

\section{La elaboración del duelo y las dificultades del desligamiento en el pós-término de análisis}

Resumen: La autora analiza las dificultades del término de los análisis, como equivalente a un estado de duelo que tiene caracteres especificos, considerada, entre otros contenidos teóricos, la idea de Melanie Klein (1991):"el término de un análisis reactiva en el paciente situaciones más arcaicas de separación y tiene la naturaleza de un experimento de destete" (p. 65). Además, estudia también el duelo por el final en el universo de los analistas, teniendo en cuenta el análisis didáctico y la especificidad de esa relación: los candidatos pueden esperar mantener relaciones con sus compañeros analistas después del término; pero los pacientes, normalmente, no pueden esperar ningún tipo de contacto. Así, es probable que el paciente sufra una reacción de dolor del duelo más intensa que los candidatos. Todas esas consideraciones ayudan a demostrar que el duelo es un importante tema a considerar en los estudios psicoanalíticos sobre el término y el pós-término de los análisis.

Palabras clave: Psicoanálisis. Duelo. Término de análisis.

\section{Referências}

Balint, M. (1950). On the termination of analysis. The International Journal of Psychoanalysis, 31, 196-199.

Balkoura, A. (1974). The fate of the transference neurosis after analysis scientific proceedings: Workshop report. Journal of the American Psychoanalytic Association, 22, 895-903.

Bergmann, M. S. (1988). On fate of the intrapsychic image of the psychoanalyst after termination of the analysis. Psychoanalytic Study of the Child, 43, 137-154.

Bick, E. (1991). A experiência da pele em relações de objeto arcaicas. In E. B. Spillius (Ed.), Melanie Klein hoje: desenvolvimentos da teoria e da técnica (Vol. 1: Artigos predominantemente teóricos, pp. 194-198). Rio de Janeiro: Imago. (Trabalho original publicado em 1968) 
Conway, P. S. (1999). When all is said: A phenomenological enquiry into posttermination experience. International Journal of Psychoanalysis, 80, 563-574.

Craige, H. (2002). Mourning analysis: The post-termination phase. Journal of the American Psychoanalytic Association, 50, 507-550.

Ferraro, F., \& Garella, A. (1994). Formas del proceso analítico y terminación. Revista de Psicoanálisis, 3(Número Especial Internacional), 77-96.

Freud, S. (1975). Análise terminável e interminável. In S. Freud, Edição standard brasileira das obras psicológicas completas de Sigmund Freud (Vol. 23, pp. 247-287). Rio de Janeiro: Imago. (Trabalho original publicado em 1937)

Goldberg A., \& Marcus, D. (1985). "Natural Termination”: Some comments on endings analysis without setting a date. The Psychoanalytic Quarterly, 54, 46-65.

Green, A. (2000). Le temps éclaté. Paris: Les Éditions de Minuit.

Guignard, F. (1997). Le temps d'après. Revue Française de Psychanalyse, 61, 1215-1223.

Klein, M. (1991). Sobre os critérios para o término de uma psicanálise. In M. Klein, Inveja e gratidão e outros trabalhos: 1946-1963 (As obras completas de Melanie Klein, Vol. 3, pp. 64-69). Rio de Janeiro: Imago. (Trabalho original publicado em 1950)

Lacan, J. (1966). Écrits. Paris: Seuil.

Miller, I. (1965). On the return of symptoms in the terminal phase of psycho-analysis. The International Journal of Psychoanalysis, 46, 487-501.

Novick, J. (1976). Termination of treatment in adolescence. Psychoanalytic Study of the Child, 31, 389-414.

Parres, R. (1950). Notas sobre terminación de analisis. México: Asociación Psicoanalítica Mexicana. (Texto não publicado)

Pellanda, L. E. C. (1991). A fase pós-análise: vicissitudes de um luto. In 13 Congresso Brasileiro de Psicanálise (p. 107-120). São Paulo, SP.

Rank, O. (1924). El trauma del nacimiento. Buenos Aires: Paidos.

Reich, A. (1950). On the termination of analysis. The International Journal of Psychoanalysis, 31, 179-183.

Rickman, J. (1950). On the criteria for the termination of an analysis. The International Journal of Psychoanalysis. 31, 200-201.

Rosenfeld, H. (1988). Impasse e interpretação. Rio de Janeiro: Imago. (Trabalho original publicado em 1987)

Saigh, Y. (2002). Término de análise. Dissertação de mestrado, Departamento de Psicologia Clínica, Pontifícia Universidade Católica de São Paulo, São Paulo.

Schmideberg, M. (1938). After the analysis. The Psychoanalytic Quarterly, 7, 122-42.

Segal, H. (1998). Psicanálise, literatura e guerra: artigos 1972-1995. Rio de Janeiro: Imago. (Trabalho original publicado em 1997)

Sheppard, A. (1998). Forced Termination. Journal of Melanie Klein and Relations, 16(1), $125-146$. 
Ticho, E. A. (1972). Termination of psychoanalysis: Treatment goals, life goals. The Psychoanalytic Quarterly, 41, 315-33.

Yeda Alcide Saigh, Membro Efetivo e Docente da Sociedade Brasileira de Psicanálise de São Paulo, Doutora em Psicologia Clínica pela Universidade de São Paulo. Endereço para correspondência: Rua Laconde, 3 - Jardim Europa - São Paulo, CEP:01448-040,Tel: 3083.5795. Endereço eletrônico:ysaigh@uol.com.br

Recebido em: 31/01/2008

Aceito em: 12/09/2008 